\title{
Embedding quantitative skills into the Social Science curriculum: case studies from Manchester
}

\author{
Jennifer Buckley, Mark Brown, Stephanie Thomson, Wendy Olsen and Jackie \\ Carter
}

Social Statistics, University of Manchester, Manchester UK

Corresponding author: Jennifer Buckley, Social Statistics, Humanities Bridgeford Street,

University of Manchester, Manchester M13 9PL . Jennifer.buckley@manchester.ac.uk

\begin{abstract}
Those aiming to respond to the recognised shortage in quantitative skills within the UK social sciences have increasingly focused on the content of undergraduate degree programmes. Problems occur when -quantitative methods (QM)- are generally confined to a dedicated module, detached from substantive topics. This model makes it hard for students to understand or engage with the contribution of quantitative research to their discipline and can perpetuate negative perceptions of quantitative training. We suggest a solution to this problem is 'quantitative embedding', in which quantitative evidence and methods are incorporated into substantive teaching in the social sciences. We illustrate quantitative embedding with case studies from an ESRC funded project based in The University of Manchester, where teaching partnerships have developed curriculum innovations in Sociology and Politics. The paper then discusses the challenges of disseminating quantitative embedding, highlighting the need to bridge separate -communities of practice- that can isolate quantitative specialists.
\end{abstract}

Key words: Pedagogy, quantitative embedding, quantitative skills

In recognising a shortage of quantitative skills in the UK Social Science community, scholars have highlighted shortcomings in the way quantitative methods (QM) are taught in undergraduate programmes (Falkingham \& McGowan, 2011; MacInnes, 2009; Parker, Dobson, Scott, Wyman, \& Landén, 2008). These reports observe that while on most programmes some quantitative training is now compulsory, for many students it is something detached from the rest of their degree, lacking relevance to the major disciplinary themes 
covered in their substantive courses. This observation may highlight a problem with the methods courses themselves, which tend to teach the mechanics of data analysis. Equally, it might be because much 'non-methods' teaching lacks quantitative examples and references to the contribution of quantitative approaches to subject knowledge-and understanding. Against a background of widely reported student anxiety over quantitative data (Adeney \& Carey, 2011; Howery \& Havidan, 2006; Slootmaeckers, Kerremans, \& Adriaensen, 2014; Williams, Payne, Hodgkinson, \& Poade, 2008), the marginalisation of quantitative evidence in substantive teaching is a clear obstacle to getting students to see quantitative methods training as anything more than a module to be got through.

In the UK, alienation from quantitative methods among undergraduates may reflect the wider marginalisation of quantitative methods within parts of the social science research community. For example, a content analysis of leading sociology journals in 2004 found that less than 9 percent of papers with empirical content used quantification (Payne, Williams, \& Chamberlin, 2004). Despite major initiatives to increase quantitative training at postgraduate level, Wiles, Durrant, De Broe, \& Powel (2009) found that the 'anti-quantitative' attitudes observed among Social Science undergraduates were also evident among doctoral students, with less than a quarter of Sociology and Politics students using any quantitative data in their PhDs. This concerning state of affairs threatens the motivation and ability of a new generation of social scientists to engage with some of the classic texts in UK social science or with (such as the work of Goldthorpe, 1987) and-quantitatively advanced outputs eoming out effrom the USA.

In response to the quantitative deficit in the undergraduate curriculum, this paper discusses an approach for teaching social science research methods where quantitative data and methods are embedded within the substantive curriculum. In presenting this approach, we are keen to dissociate from any position-suggestion that portrays-quantitative approaches 
areas superior to qualitative methods and traditions (for a discussion of this, see Byrne, 2012) and reject as unhelpful any framing of the debate in terms ofas a quantitative versus qualitative methodological divide. Instead, our case for embedding quantitative data and methods in the substantive curriculumwe emphasises how embedding can help students develop the skills and experiences they need as social scientists to evaluate the usefulness of various methodological approaches. Through examples from an ESRC_-funded teaching project based at the University of Manchester, UK, we discuss what quantitative embedding can look like in practice and the collaborative teaching partnerships that have been a key component of our model. We then evaluate our experiences of embedding and review the challenges and opportunities involved in adopting such a model of quantitative embedding across the Higher Education (HE) community.

\section{The case for quantitative embedding in the substantive curriculum}

Our approach developed in response to feedback from students that methods teaching seems divorced from the rest of the curriculum, and is something-to be endured rather than enthused about (MacInnes, 2009; Wathan, Brown, \& Williamson, 2011; Williams \& Sutton, 2011). Based on the study by Williams et al. (2008), a survey of second year sociology students confirmed there was high anxiety around the use of statistics and a common perception that quantitative research examples are infrequently used in other course units. LIn the UK, low prior mathematics attainment could be a contributory factor. For example, aA study for Nuffield-Hodgen, Pepper, \& London (2010) confirmed that among the 24 countries studied in the study the UK had the lowest proportion studying maths post age 16 (Hodgen, Pepper, \& London, 2010). However, we view the failure to establish the relevance of quantitative skills as a greater barrier, a pesition taken byechoing others in the field (Adeney \& Carey, 2011; Chamberlain, Hillier, \& Signoretta, 2014; Williams et al., 2008). This is not to deny the importance of mathematical knowledge in methods teaching but rather weto question whether 
'more' school mathematics is likely to make a difference to students' attitudes towards and attainment in research methods.

In teaching research methods, we are asking students to do more than simply perform calculations. We try to teach students to become confident and critical interpreters of data se that they can both perform independent research and appraise the research of othersfor their methodological competence and literacy. Thus, we aim for students to gain conceptual understanding of methodological issues and not just procedural competence-in particular methods. In essence, we face similar problems to these of school mathematics teachers: how to engage students and give them a 'relational' rather than 'instrumental' understanding of mathematical-concepts (Skemp, 1976). A suggestedOne approach, well-articulated in a study ef primary mathematies teachers, is to employ 'connectionist teaching' practices (Askew, 1997). Connectionist teaching encourages students to acquire a more complete understanding of an idea or concept through an active learning process that gets studentsto actively considering how the idea or concept relates to other ideas and concepts-(Askew, Brown, Rhodes, Johnsen, \& Wiliam, 1997);. In connectionist teaching, sstudents are encouraged to evaluate the appropriateness of different techniques (Askew, Brown, Rhodes, Johnson, \& Wiliam, 1997)(Askew et al., 1997). In contrast, 'transmissionist' teaching prioritises the learning of techniques and processes, which can then be applied in a variety of situations. A key difference between these two styles, represented here in their ideal form, is the role of examples in learning. -For connectionist teachers, examples play a key role in the learning process as students become aware of the role of context in informing their approach to problem solving-and making the links between different elements of mathematics. By contrast, for transmissionist teachers, examples provide a valuable opportunity to practise processes whichthat have been learned already. 
As Vygotsky (1987) argues, understanding the relationship between a specific example and an abstract idea is essential to concept formation. Moreover, true conceptuat understanding occurs when we can reconcile the complexities of a particular instance with our schematic thinking. Methods teaching that is independent of substantive teaching asks students to learn and apply abstract, generalised ideas rather than giving students theproviding opportunitiesy to develop deeper, conceptual understanding through the use of detailed, rich examples. Any conceptual understanding that does-develops independently of real examples risks being incomplete and can lead students to see concepts, and indeed conceptual thinking, as divorced from their main interests (Vygotsky, 1998). Vygotsky's ideas give usprovide a plausible explanation for what we see in practice with methods courses when students find the content detached from reality and hard to learn-(MacInnes, 2009; Wathan et al., 2011; Williams \& Sutten, 2011).

The 'connectionist' teaching strategies favoured by some in-mathematics educatorsion may offer a useful way forward. Since-Organization of the school curriculum is - organised into separate, examined subjects and teachers need to prepare students for exams, examples of 'connectionist' teaching in schools are-rare. However, a key development, Realistic Mathematics Education (RME), has been shown to improve problem--solving skills in school childrenpupils and increase their interest and confidence in mathematics. ${ }^{1}$ The challenge, then, is how to implement such an approach in a university settingHE to ensure examples allow conceptual understanding to oceur-and allow-more active learning by students. We could reasonably expect methods teachers to develop materials using examples from their own fields, but not across all subject areas. Moreover, compartmentalising

\footnotetext{
${ }^{1}$ See Van den Heuval-Panhuizen and Drijvers (2014) for more on RME and Searle and Barmby (2012)
} for an evaluation of an RME teaching approach in the UK. 
methods teaching sends a message to students that the context of a problem is less important than the abstract, generalizable principles that underpin the methods used.

Alongside others we suggest a way forward in universities is topropose building bridges between the teaching of methods and substantive course units and that this bridge building should includinge the embedding of some aspects of methods teaching into substantive course units (see also Adeney \& Carey, 2011; Falkingham \& McGowan, 2011; Hampden-Thompson \& Sundaram, 2013; Slootmaeckers et al., 2014). Encouragingly, as embedding has become more widespread, studies are producing evidence that the opportunities to learn using data in particular social science contexts can have a positive effect on student attitudes and attainment. Notably, a recent study by Slootmaeckers, Kerremans, and $\&$ Adriaensen (2014) found that students encountering quantitative methods in substantive courses had reduced anxiety over statistics and greater retention of statistics skills.

We further suggest that embedding allows students to develop what Bloom (1956) terms higher-order thinking skills. Bloom (1956), drawing on Vygotsky, suggests that thinking skills vary in difficulty from lower-order skills needed to learn new terms or facts through to higher-order skills needed to evaluate evidence. Course units dedicated to teaching quantitative methods, as they are usually constructed (Parker et al., 2008), start by giving students the opportunity to acquire skills in, what Bloom (1956) terms, the knowledge class of the cognitive domain. Students learn new terminology, processes to follow and perhaps technical skills in statistical software. Eventually, they are expected to analyse data and make statements about the relationships between variables, thus demonstrating skills in the analysis class of the cognitive domain. In an embedded model, the problems that a data analyst faces are explored, not just as technical issues, but as real, substantive challenges that require critical attention. In this way, our model situates quantitative data and methods within a 
broader culture of scholarship where assertions are challenged and the quality of evidence assessed.

There is a clear case for embedding aspects of methodological teaching in the substantive curriculum; however, this part of the solution is not straightforward to implement. To be successful, embedding activities must be well-planned so that students are able to draw on appropriate materials and exercises to aid their learning. Conversely, as Slootmaeckers, Kerremans, \& Adriaensen (2014) suggest_B badly developed embedding materials and activities have the potential tomay reinforce students' negative perceptions of statistics-as at difficult topic (Slootmaeckers, Kerremans, \& Adriaensen, 2014). In the following three sections, we outline how embedding might work in practice with reference to the model developed within our own institution and particular examples of teaching innovations.

\section{Embedding in practice}

Our institutional response to the problem of teaching QM started with the existing methods classes. In particular, the core sociology unit was redesigned to mimic the process of doing social research. In our revised model, students learn how to develop and explore theoretically informed and substantively interesting research questions with real survey data. The producing and interpreting of statistics in the practical classes (primarily using SPSS) is thus underlined by clear substantive research goals. For example, we have used the Health Survey for England to explore gendered aspects of obesity and attitudes towards weight and, the British Crime Survey to investigate the social determinants of the fear of crime-and British Social Attitudes to examine changing attitudes towards welfare in 'an age of austerity'. Engendering the excitement of the research process means students curiosity about the data and questions helps counter the anxiety many have about statistics. As well as offering an engaging and disarming way of introducing statistical concepts and techniques, this model-also helps installfosters a critical approach to data and analysis, as the specific research 
contexts require students tonecessiate considering issues such as question design, nonresponse and coding decisions. The changes resulted in clear improvements in student evaluation and.Following the redesign, the previously unpopular course was unit became one of nine in the School of Social Sciences to be-commended for attaining feedback scores in the top 10 percent of all undergraduate course units in the Faculty-of Humanities. Whilest this was a clearly positive outcome-was achieved, our rationale is that even, a well-designed and received methods course is not sufficient; a point similarly emphasised by as Chamberlain et al. (2014), whe found that even when a student group rates their methods training highly, most students remain anxious about leaning statistics and lacking confidence in their numeracy skills.

The second element of our strategy focuses on building links in the other direction by embedding quantitative data and research throughout the degree programme. Similar to the approach of Falkingham and\& McGowan (2011), a central aspect of our model are collaborations between the project team and lecturers. In our case, the project team comprises experienced methods teachers, a specialist in mathematics education and experts in data support services. The partner lecturers participated voluntarily and are all from Politics and Sociology, social sciences discipline areas identified as having the greatest need in the UK for more QM training (MacInnes, 2009). We recognise that this model of teaching partnerships is rarely found naturally in institutions and must be carefully managed. Wenger's (1999) notion of communities of practice is helpful here because it can help us understand how sub-groups within institutions set their own norms and develop their own ways of working which may-be different to that of otherbetween from other sub-groups. In eur institution, all partner lectures participated voluntarily. The teaching material is then constructed through a collaborative partnership, where the substantive lecturer directs the nature and focus of the embedding intervention. This approach aims to ensure-tailor new 
content is tailored to the specific -course's learning aims and objectives-of the course unit eoncerned. TWe propese that the benefits of such collaborations to beare mutual. These involved in methods teachingMethods teachers benefit as students begin to encounter quantitative data and concepts regularly in substantive course units. For the substantive lecturers, these collaborations can where lecturers provide extensive additional resources, including expertise and time, which theythat can $u s e$ to enrich their teaching.

Table 1 summarises the embedding activities developed through 13 teaching partnerships across two academic years. A common element of the collaborative process was a series of consultations between the project team and course unit convenors. The consultation process followed a distinctive path for each partnership but always focused on identifying aspects of the current curriculum that could be enhanced by the integration of quantitative data and methods. Consultations typically started in April to ensure materials could be developed and integrated into the curriculum for the start of term in September. However, collaborative arrangements varied to accommodate the timescale of each partner and the nature of embedding activities, which sometimes needed to be created in parallel with the teaching. As Table 1 shows, collectively our teaching partnerships drew upon an extensive range of data to develop diverse embedding materials and activities. To illustrate both the diversity of activities constituting quantitative embedding and some core themes, the next section discusses specific case studies from the project.

TABLE 1 ABOUT HERE

\section{Case studies of quantitative embedding}

Our examples of quantitative embedding are not intended to constitute a one-size fits all version of 'best practice'. In fact, we suggest that $\underline{\text { Such a }}$ prescriptive notion of 'best practice' is unhelpful in thise context-of an embedded approach to QM teaching. For instanceInstead, we must consider how the student intake in the social science course units is very 
variedvariations in student intake and teaching must be adapt teachinged to the particular skill level of the group. Secend, a $\underline{A}$ notion of 'best practice' may devalue perfectly successful alternative methods of teaching and stifle innovation. AP Potentially, accepting a paradigm of 'best practice' may alseMoreover, it may serve to create a power_imbalance in collaborative relationships. Thus, are suggesting that it is possible to learn from the experiences of seasoned practitioners without accepting that there is one, best approach.

\section{Making students 'part of the data-set'}

Our first example developed through the collaborative partnership to introduce quantitative data and methods to a large politics course unit, Introduction to Comparative Politics. The large cohort taking the course unit-contains students at different stages and different degree courses: the course unit is compulsory for level 1 students in Polities and an option for other students in their first and second-year. In this partnership, the consultation process established an opportunity to build teaching materials linking with the research of one of the course lecturers. The lecturer had been involved in developing survey questions on attitudes to immigration for the British Social Attitudes (BSA) survey. These questions were added to a simple_online survey_-on Blackboard, the course virtual learning environment (VLE). Students completed the surveyfor completion prior to the lecture and we compiled the student data with data for the British public and graduates from the 2011 BSA survey. This exercise makes students 'part of the dataset' and demonstrates the research process moving through the stages of question design through to data collection and data analysis. The survey instrument, exercise of data collection and the resulting dataset provides the basis for a linked tutorial built around how attitudes towards immigration vary between the students in the class and the British public.

In this model, statistical concepts and techniques are implicit to the exercise but the focus is on answering substantively interesting questions. Students tend to show high levels 
of engagement with data measuring their attitudes and how they, as a group, vary from the general population. In turn, seeing such attitudinal differences emerge helps students to appreciate the problems of generalising from their own experiences and to think about the social processes producing such differences. The exercise enables a host of related and methodologically important concerns related to survey design to be considered in context as they arise. By mimicking the research process, the exercise enables conversations about the limitations of data and the process through which it is generated. For instance, students can input their own experience of answering the questions, when discussing if the questions measure attitudes reliably.

\section{Hands-on with data}

The 'making student's part of the dataset model' has been adapted for use in other course units by introducing a practical computer workshop. In another first year politics course unit, Research and Study Skills, students develop a small research project or proposal based around a substantive theme selected for each year (examples include inequality and civic participation). As in the earlier example, we surveyed students using themeThis is again

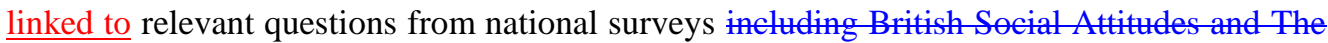
British Election Study. However, in this applicationbut, rather than providing students with the national results in the form of prepared tables, we developed a practical computer workshop in which students access the survey data using online interfaces. ${ }^{2}$ Students can use these online interfaces without prior software training in a data analysis package such as SPSS. They therefore offer a rare opportunity to incorporate hands-on data work into a substantive course where there may be limited timetable space and access to computer clusters. A single hour session using these interfaces saw students confidently generate and

\footnotetext{
${ }^{2}$ The British Social Attitudes Information System at http://www.britsocat.com/ and the British Election Study Information System at http://www.besis.org/.
} 
download bespoke tables for a range of variables. As well as sourcing national results, $t$ The practical workshop_also guided students to compare population sub-groups using simple cross-tabulations and to source data for their project work. Enabling $\underline{B}$ y enabling students to work hands-on with real data early in their studies helps engage-interest is engaged and build confidence built, in using quantitative data and methods. Thus, these experiences can motivate and-preparinge students for more formal training in data analysis. In this specifie case study, the clear link to formallyformerly assessed work is important and arguably needs to be considered in all quantitative embedding work if it is to bringfor meaningful change necessitating. Unless incerporated into assessment activities students may lack the incentive to fully-engagement with quantitative material. This in turn, raises the need to ensure that the associated skill set is explicitly written into learning outcomes, both at the unit and course level.

\section{An empirical evidence base to critique theory}

A further effective approach to embedding is to provide an empirical evidence base to support critical engagement with theories presented in the substantive course unit. This approach was used in several course units-at different levels and in both Polities and Sociology. The first teaching partnerships to use such an activity related to a level 1 course unit on the sociology of personal life, taken by single- and joint- honours students in Sociology. The collaboration created materials for use in a lecture and tutorial on 'living alone'. Based on data from the UK social survey Understanding Society, a series of tables gave insight into the characteristics of those living alone and how they compare to those living in other household arrangements. Along with the theoretical background provided by the lecture and tutorial reading, this empirical evidence supports discussion around the topics of stigma, stereotypes and social norms and how they connect with gender and life stage. 
With a clear focus on the substantive questions being addressed, the tutorial exercise introduces first year-students to quantitative data as an integral part of sociological study. Students are engaged in learning and applying key quantitative concepts and skills such as the reading of percentage tables and the basic skills used to read the story of a table or graphwhich can be extended by, for example, showing how to calculate ratios as an aid to making comparisons. The tutorial also provides opportunity to discuss key methodological issues by asking students to critically reflect on the measurement and categorisation of living arrangements, socio-economic classifications and concepts such as life satisfaction. Having used the data to profile the characteristics of those living alone, we can ask students to reflect on the reasons for the patterns observed and how they relate to theoretical ideas they are learning. In this way, analytical concepts such as association and causality can be introduced with reference to real data and to the substantive theme. If suitable, these critical reflections can provide a useful context to introduce more challenging ideas, for example, showing some of the tables with confidence intervals added can facilitate the discussion of statistical significance.

To support the embedding activity, we developed explicit learning outcomes for both class roem activities (very concrete) and for chunks of learning (more abstract). For example, task level learning outcomes indicate that a student should have learned to 'discuss at percentage' and 'realise the diversity that is hidden beneath an aggregated percentage figure'. At the level of the course unit, learning outcomes can specify that student should have learned to 'critique measurement of stigma', 'examine competing measures of well being and 'relate a social theory to an empirical hypothesis'. We found the use of explicit learning outcomes helpful in two ways. First, it helped teaching assistants and lecturers to work in a team focused upon the agreed objectives of each activity. Second, the explicitness of the learning outcomesit helped students realise what a strong performance would look like to the 
teacher. Whilst theory is important in sociology, it became possible to say precisely what would be valued in introducing empirical data or a critique of measurement into an essay or exam. In the end, it was possible to increase the expectation that students should include empirical evidence in their essays or exams.

The teaching partnership for a final year Sociology course unit Power and Protest provides a further example of this model of embedding. In this partnership, we worked with the lecturer to develop an evidence pack for a class debate in a week of the course focused on political participation and apathy. As a development to the previous example, wWe provided students with a range of empirical data with which to discuss and critique different theoretical positions, which were set out in from a preceding lecture. This evidence pack took the form efcomprised a time series of simple tabulations of survey measures of participation crosstabulated by age, sourced from selected surveys including British Social Attitudes-(BSA) and the Hansard Society's Audit of Political Engagement. The data in the evidence pack showed various patterns in political participation and, as a result, students gained experience of selecting appropriate evidence to form an argument and the multi-dimensionality of complex concepts such as political engagement. In the second year of running the workshop, we added the task of sourcing evidence using the online interfaces discussed earlier. This independent activity, which was supported with a guidebook, only-provided students with an opportunity to get students-working hands-on with the original data sources but alsoand to practise skills relating to the sourcing and presentation of evidence.

The examples discussed here share obvious similarities. Central to all is the inclusion of empirical data to enrich teaching on substantive themes. In our teaching partnerships, we draw heavily on the wealth of UK social survey data, which can be accessed free of charge under academic licence from the UK Data Service. Additionally, the use of online tools has 
enabled both staff and students to access data without needing to use statistical packages. The eutputs used are generally simple tabulations, incerporated into lecture slides and as the basis for thtorial activities and discussion. These $\Theta$ Outputs engage students in some common QM learning activities but also address learning objectives relating to measurement, comparison and the relationship between theory and evidence. When repeated across course units, these forms of embedding can help establish familiarity with quantitative approaches whilest developing confidence in the basic skills required of a critical reader of quantitative evidence. This embedded approach is therefore giving the important subject-specific opportunities for reflective learning on the strengths and limitations of quantitative data and methods to a field of study.

\section{Evaluation of embedding}

In our collaborative model of embedding, we have tried to assess initiatives from the perspective of all communities of practice involved. This evaluation process incorporates both reflective practice and more formal methods including staff interviews and student surveys and focus groups. We use this process to continually inform revision of materials and approaches to curriculum innovation.

First, reflections on the partnerships and embedding activities by the project team have produced several outcomes that are important to note. A foremost positive outcome is that the collaborative partnerships produced materials that have been used, re-used and alse further adapted. It is however, necessary to recognise that nNot all proposed partnerships came to fruition or led to successful quantitative embedding. In our case, the voluntary partnerships did not experience any of the resistance to including quantitative materials that Falkingham and $\&$ McGowan (2011, p. 114) had found using a similar model. Instead, the two main barriers we encountered were competing time pressures on staff and staff leaving the institution. However, an unexpected but positive outcome was that the project engendered 
additional interest from teaching staff not originally involved. This welcome development did, however, present its own challenges given the finite resources of our project budget. In general, preparing materials for embedding work is time consuming and collaborative partnership working required the dedicated time of the project team. Thus, the additional interest quickly emphasised the challenge of developing sustainable strategies for resourcing such activities beyond the set-up funding period (and in other institutional settings). One method we tried was to employ Social Statistics PhD students in the discipline of Social Statisties-to source data and develop materials under the guidance of the partner lectures. This provided an effective and highly flexible model with which to respond to increases and variation in demand across the academic year but still required significant financial resources (typically around twenty hours of research assistant time per module).

While acknowledging the resource intensive nature of this type of curriculum development, we are finding that once successfully incorporated within a course curriculum, embedding activities can be sustained without major re-investment of resources. Most of our interventions have re-run with minimal involvement of the project team and, in some cases, even following changes to the course convenor. We did, however, experience some difficulties in the re-use of embedding activities with new staff new to a course unit-needing the aims and outcomes to be clarified. This problem has perhaps been most acute with teaching assistants taking tutorials or seminars on the larger course units. From our experience, features that appear to support the longevity of embedding materials are clearly specified activities with specific learning outcomes that can be understood by new convenors, and where applicable the teaching assistants. However, it may also be that in some circumstances ongoing support and training is required.

Finally, whilst we did not experience direct resistance to embedding as others have done (Falkingham \& McGowan, 2011), our project suggests there are limits on the types of 
quantitative data and methods that can be embedded. As the examples show, our embedding activities incorporate only basic level numerical tasks-such as reading and calculating tables ef percentage, with the emphasis on critically interpreting data. Rather than reflecting any explicit decision to avoid introducing more difficult QM topics, such as regression, the nature of embedding activities results from individual decisions made through the collaborative partnerships about what would be appropriate for the specific teaching context. A number of the partner lecturers stressed the limited availability of time and space within the unit curriculum, and felt that it would be difficult to increase the level of statistical content without sacrifices to the existing substantive content. A further concern expressed was whether students would have the necessary prerequisites to work with more advanced QM concepts and methods, especially as course units in Politics and Sociology attract students from other disciplines and schools.

In terms of student evaluation, our use of questionnaires for each of the partner course units encountered problems of low response rates. In particular, attempts to use online surveys were particularly unsuccessful and, as a result, our evaluation data comes from a small selection of course units where data was collected using paper based questionnaires. The questionnaires were distributed and completed during a lecture or tutorial in the last teaching week of the course unit. This approach to data collection produced much better response rates but the samples consist only of students attending the classes. In total, wWe obtained 73 completed questionnaires from students in three course units. Response rates reflect the proportion of students completing questionnaires within each class and range between 53 percent and 80 percent, see note to Table 2 for further details. While acknowledging that our data is not fully representative of the student body, it affirms that the initiative has been well received in the classroom. Table 2 shows that the majority of students surveyed have positive responses to quantitative embedding and that they appreciate the use 
of well-selected examples to help them learn about both quantitative research and substantive theory.

\section{TABLE 2 ABOUT HERE}

There was clear support for including On the general question of whether quantitative training should be included-in social science degree programmes, there was clear support. For example, $\Theta \underline{O}$ nly 1 in 5 agreed that social science students should not have to study statistics, and 4 in 5 indicated that learning quantitative skills was a useful part of a degree programme. Students agree that learning to interpret quantitative data and topics can provide a range of benefits. Such benefits related to academic study such as-(forming convincing arguments, doing research and making a subject more interesting) and. There was also recognition of the benefits outside of academic study, with a large proportions indicating that learning to interpret and analyse quantitative data can help with-beyond (understanding statistics in the media and getting a good job). These themes also emerged in the qualitative feedback with students emphasising the presence of numerical data in other aspects of life:

When you're getting out of university and going forward a lot of what you're doing is looking a numbers and having to make a judgement. Your world is not going to be devoid of numbers. It is important and would be valuable addition to a degree

Focusing on quantitative embedding, student feedback has been primarily positive towards both principal and practice. The qualitative evidence especially points towards students recognising a preference for contextualised encounters within quantitative evidence.

Integrated into what you are doing so it doesn't feel like you're doing quantitative data for quantitative data's sake. Say in politics there is a really important survey that is related to exactly what we're learning about and then you say were going to interpret this in this way; then it doesn't really feel like we're doing it because it's so interlinked and that's the point of quantitative data any way, that it's just done as part of all your other research 
Moreover, students report finding the use of data helpful in bringing theories alive and making them seem less abstract. This positive feedback is evident in the survey data, as $t$ The majority of surveyed students-respending agreed that the embedded content helped them to make sense of the theory and that it related to the main topics well. The theme similarly emerged in the qualitative feedback, as illustrated well in a comment fromSimilarly a student on the Power and Protest course unit commented:

\section{I found it extremely useful to learn about the theory and then have some real life contextual evidence to engage with - it makes the theories feel more worthwhile learning about. Sometimes I feel that it is easy to forget that the theories we learn about in lectures are actually real life issues that really do effect the way that people live their lives, their opinions and actions.}

These attitudes and perceptions of students indicate that the teaching partnerships can successfully develop quantitative materials that reinforce existing learning outcomes.

Whilest nearly all students surveyed indicated that there were benefits to learning quantitative skills, there is evidence that -a minority were less favourable about their experience of quantitative embedding. For instance, in the survey, nearly 20 percent of surveyed students indicated they found the quantitative element difficult to understand, 25 percent did not enjoy the new activities and 13 percent found they distracted from the main course unit themes. In one of the focus groups, a student explained how they missed a seminar because they felt ill-prepared as a result of being unable to calculate a percentage. These findings from the student evaluation findings underline how some students will feel challenged and potentially isolated by the inclusion of quantitative data in the curriculum. Such a finding has varied implications for embedding. On the one-hand, quantitative embedding is potentially the best approach to supporting students likely to struggle, especially when teaching partnerships utilise the skills of both QM experts and substantive teachers to present quantitative training in an accessible and engaging way. However, the 
repeating of quantitative content could help to alienate students struggling with high levels of statistical anxiety (Slootmaeckers et al., 2014).

WFinally, we are keen tohave been monitoring some positivethe impacts of the curriculum change on student decisions to further engage with quantitative data, including a gradual increase in the numbers of students undertaking quantitative dissertations. We have long been aware that despite training students in the skills needed to conduct quantitative research in their dissertations very few students opt to do this in their final year dissertations. For the 2011-12 academic year, an audit of dissertations in Politics and Sociology confirmed the perception by revealing that just one student (out of ??) studenthad undertaken secondary analysis of survey microdataa quantitative dissertation. Encouragingly, a similar audit two years later indicated the number opting for secondary quantitative analysis had increased to 15 (out of 118). Similarly, there has also been a gradual increase in the number of students taking further quantitative options in their third year of study including a new third year course on modelling inequality using regression (with enrolment going up from seven to nearly 30 in its second year of running) .

\section{Adopting the embedded QM model: challenges and opportunities}

Our project focused on solutions to the challenges of teaching quantitative methods in one institution. In this final section, we use our experiences to consider the challenges and opportunities others might face in adopting a similar model of embedding. First we argue that an embedded approach to QM learning requires change not only among methods teachers and not only at the level of individual course units. -Within departments and at programme level, non-methods teaching staff need to buy into the benefits of embedding and the contribution of QM in their subject area. They must also be prepared and able to invest 
scarce time on the revision of course units, which they may feel are already adequate. Crucially, there must also be a willingness among substantive social science teachers and QM experts to collaborate.

Meeting the first of these conditions is likely to be much harder in some institutions than others, depending upon the particular methodological traditions and the extent to which there are QM specialists within teaching groups. The University of Manchester is in a relatively advantaged position as we can draw on a history of inter-disciplinary collaboration between Sociology, Politics and Social Statistics, as well data expertise in the UK Data Service and now the British Election Study (BES) and Q-Step team. In institutional settings where QM is more marginalised in research and teaching, initiatives of the type may be much harder to implement, even extending to some resistance on intellectual grounds (Platt, 2012). Given the strongly qualitative traditions of many departments and wariness, if not resistance, to the teaching and use of quantitative methods, it is crucial that initiatives such as the Manchester project are not seen as attempts to impose QM or to suggest that QM approaches are epistemologically or methodological superior to other positions ${ }^{3}$. Rather, we argue that basic quantitative skills are essential for any social scientist in order to understand and make an informed critique of research contributions to a field. Moreover, we also seek to-emphasise how in a period when many social science departments are looking to extend the QM training provided in undergraduate degrees, a response that focuses only on methods teaching, risks exacerbating the current problems of students feeling disconnected and alienated from methods. From our experiences, a model of collaborative teaching partnerships offers a promising vehicle for this interpretation of embedding as the substantive content of the course remains pivotal.

\footnotetext{
${ }^{3}$ This is a worry expressed by, amongst others, Byrne, 2012.
} 
Resources are undoubtedly a key constraint in adopting an embedded model. The development of engaging materials for embedding requires resources such as-time and expertise, and it is an important question whether this approach is replicable without dedicated grant or other funding. For most $\mathrm{HE}$ lecturers-working in higher education, time for course development can be hard to prioritise against competing demands-of research and the delivery of core teaching. We therefore-argue, therefore, that curriculum development needs to be built more explicitly into work allocation models and incentivised. Within the current context, however, an advantage of our model of embedding is that curriculum change is incremental: innovations can be focused on specific course units, even just a specific topic, lecture or seminar. As a result, embedding can be part of a routine process of course unit revision as convenors perceive a need for change or opportunity for improvement.

Our model of embedding builds on local level collaboration and considerable sharing of expertise between QM specialists and substantive lecturers. A sustainable strategy for embedding must therefore identify ways to support such collaboration. In our case, the grant funding was significant in enabling quantitatively trained staff to devote the time needed to share their expertise in sourcing and preparing embedding materials, a model that continues as part of the Manchester Q-Step programme. Without such funding our model of collaboration is more difficult to adopt. Moreover, we recognise that the presence of quantitatively trained staff is undoubtedly a variable factor across institutions; as is the extent to which those with QM expertise are integrated within departmental teaching cultures. QM specialists often collaborate in research with $\mathrm{QM}$ skilled staff from other schools or institutions and, as teachers of methods courses, can be isolated in their teaching. In such a context, our model of embedding may initially be limited to small-scale local adoptions. However, where successful such initiatives may be the catalyst for bringing together new collaborations, especially where supported by changes at the institutional level. Institutional 
level changes might include organisational changes to ensure substantive and methods teaching staff come together in teaching groups, as well as offering more formal opportunities to collaborate through greater use of 'team teaching' models, both within and across discipline areas.

The resources needed for embedding suggest Open Educational Resources (OERs) could be instrumental. The benefits are especially great in teaching environments where QM expertise is lacking but they could be much wider since the sourcing and preparing of embedding materials is resource intensive. For instance, as Falkingham and $\&$ McGowan (2011) highlight, certain topics and themes (such as immigration, globalisation and poverty) are widespread throughout social science curriculums. Thus, some up-to-date, accessible and engaging material relating to such topics could be relevant across a large number of teaching contexts. There is already a sizable repository of excellent QM focused OERs (Carter, 2011, 2012); ${ }^{4}$ however, they predominately cover data analysis, and are therefore less useful resources for quantitative embedding. Their largely technical focus perhaps reflects how teaching materials tend to be designed for use within a community of practice such as the community of QM teachers. OERs designed for embedding are however becoming more common, following initiatives such as ESRC's Curriculum Innovation and Researcher Development Initiatives, including case studies and teaching materials from our own project. ${ }^{5}$

\section{Conclusion}

\footnotetext{
${ }^{4}$ See for example, Jorum (http://www.jorum.ac.uk/); ESRC's Quantitative Methods Initiative (http://www.quantitativemethods.ac.uk/); OPOSSEM, the Online Portal for Social Science Education in Methodology (http://opossem.org/), and; the Oxford Social Science QM teaching archive (http://www.sociology.ox.ac.uk/qm-teaching-materials-archive).

${ }^{5}$ Case studies and teaching materials from the project are available online under Creative Common's license ( http://www.socialsciences.manchester.ac.uk/essted).
} 
We have outlined a specific, institutional response to the problem of teaching QM to undergraduate social scientists. In order $t \underline{T}$ o make the concepts more relevant to their substantive interests, we suggest that quantitative data, concepts and methods be integrated into existing course units and not just taught separately as 'methods'. To achieve this, we suggest a framework which that emphasises collaborative teaching where the experience and skills of both substantive lecturers and methods lecturers can be harnessed to provide a wellconceived and coherent programme of study for students. Our examples illustrate different ways of embedding quantitative evidence within undergraduate teaching. The embedding activities have been designed to enhance the learning of both the substantive topic and methods. The aim is that, when presented with empirical evidence in a substantive topic, students will come to see such evidence as part of the range of possible evidence and neither inherently better or worse than other sources

One project such as ours will not address the UK QM skills shortage alone. We describe a model for embedding QM in teaching that could be adapted and adopted in other HE institutions. However, we recognise a number of if the challenges identified I the paper can be addressed.in this, not least the resistance to change. Practically, there are barriers related to resources, particularly the time required for curriculum development. Change can, however, be incremental and incorporated into general course revisions if there are the opportmnities and incentives for collaboration. We believe the resources, including both expertise and time needed, for well planned embedding activities suggest that Open Educational Resources (OERs) could play an important role. At present, the content and format of OERs are rarely suitable for embedding in substantive courses. However, if bridges are built between the 'teaching of methods' and 'substantive teaching', OERs could be instrumental if the principles and practice become adopted by an emerging community of practice. 


\section{References}

Adeney, K., \& Carey, S. (2011). How to teach the reluctant and terrified to love statistics: The importance of context in teaching quantitative methods in the social sciences. In Teaching quantitative methods: Getting the basics right. (pp. 85-99). London: Sage Publications.

Askew, M., Brown, M., Rhodes, V., Johnson, D., \& Wiliam, D. (1997). Effective teachers of numeracy. London: Kings College.

Bloom, B., Englehart, M., Furst, E., Hill, W., \& Krathwohl, D. (1956). Taxonomy of educational objectives: The classification of educational goals. Handbook I: Cognitive domain. New York: David McKay Company.

Carter, J. (2011). Jorum: A national service for learning and teaching. In G. Payne \& M. Williams (Eds.), Teaching Quantitative Methods: Getting the Basics Right (pp. 157176). London: Sage Publications.

Carter, J. (2012). How OERs can help a Strategically Important and Vulnerable Subject Area - Quantitative Social Science. Journal of Interactive Media In Education, 2(0).

Chamberlain, M. J., Hillier, J., \& Signoretta, P. (2014). Counting better? An examination of the impact of quantitative method teaching on statistical anxiety and confidence. Active Learning in Higher Education. doi:10.1177/1469787414558983

Falkingham, J., \& McGowan, T. (2011). Improving the Teaching of Quantitative Methods to Undergraduate Social Scientists: Understanding and Overcoming the barriers. In G. Payne \& M. Williams (Eds.), Teaching Quantitative Methods: Getting the Basics Right. London: Sage.

Goldthorpe, J.H. (1987). Social Mobility and Class Structure in Modern Britain. Oxford: clarendon.

Hampden-Thompson, G., \& Sundaram, V. (2013). Developing Quantitative Research Skills and Conceptualising an Integrated Approach to Teaching Research Methods to Education Students. The AISHE-J: All Ireland Journal of Teaching and Learning in Higher Education, 5(3), 901-924.

Heuvel-Panhuizen, M., \& Van den Drijvers, P. (2014). Realistic Mathematics Education. In Encyclopedia of Mathematics Education (pp. 521-525). Netherlands: Springer.

Hodgen, J., Pepper, D., \& London, C. (2010). Is the UK an outlier? London.

Howery, C. B., \& Havidan, R. (2006). Integrating Data Analysis (IDA): Working with Sociology Departments to Address the Quantitative Literacy Gap. Teaching Sociology, 34(1), 23-38. 
MacInnes, J. (2009). Final Report: Proposals to support and improve the teaching of quantitative research methods at undergraduate level in the UK. Swindon.

Parker, J., Dobson, A., Scott, S., Wyman, M., \& Landén, A. S. (2008). International Benchmarking Review of Best Practice in the Provision of Undergraduate Teaching in Quantitative Methods in the Social Sciences (pp. 1-91). Staffordshire.

Payne, G., Williams, M., \& Chamberlin, S. (2004). Methodological pluralism in British sociology. Sociology, 38(1), 153-163.

Platt, J. (2012). Making them count: How effective has official encouragement of quantitative methods been in British sociology? Current Sociology, 60(5), 690-704. doi:10.1177/0011392112440438

Searle, J., \& Barmby, P. (2012). Evaluation Report on the Realistic Mathematics Education Pilot Project at Manchester Metropolitan University. Durham. Retrieved from http://www.mei.org.uk/files/pdf/rme_evaluation_final_report.pdf

Skemp, R. R. (1976). Relational understanding and instrumental understanding. Mathematics Teaching, 77, 20-26.

Slootmaeckers, K., Kerremans, B., \& Adriaensen, J. (2014). Too Afraid to Learn: Attitudes towards Statistics as a Barrier to Learning Statistics and to Acquiring Quantitative Skills. Politics, 34(2), n/a-n/a. doi:10.1111/1467-9256.12042

Vygotsky, L. S. (1987). Thinking and speech. The Collected Works of L.S. Vygotsky. Vol. 1. New York: Plenum.

Vygotsky, L. S. (1998). Development of thinking and the formation of concepts in the adolescent. In The Collected Works of L. S. Vygotsky, Vol. 5. New York: Plenum.

Wathan, J., Brown, M., \& Williamson, L. (2011). Understanding and Overcoming the Barriers Increasing Secondary Analysis in Undergraduate Dissertations. In J. Payne \& M. Williams (Eds.), Teaching Quantitative Methods: Getting the Basics Right (pp. 121-141). London: Sage Publications.

Wenger, E. (1999). Communities of Practice: Learning Meaning and Identity. Cambridge: Cambridge University Press.

Wiles, R., Durrant, G., De Broe, S., \& Powell, J. (2009). Methodological approaches at PhD and skills sought for research posts in academia: a mismatch? International Journal of Social Research Methodology, 12(3), 257-269. doi:10.1080/13645570701708550

Williams, M., Payne, G., Hodgkinson, L., \& Poade, D. (2008). Does British Sociology Count?: Sociology Students' Attitudes toward Quantitative Methods. Sociology, 42(5), 1003-1021. doi:10.1177/0038038508094576 
Williams, M., \& Sutton, C. (2011). Challenges and Opportunities for Developing Teaching in Quantitative Methods. In G. Payne \& M. Williams (Eds.), Teaching Quantitative Methods: Getting the Basics Right (pp. 66-84). London: Sage Publications. 
Table 1: Summary of teaching partnerships, embedding activities and data sources

\begin{tabular}{|c|c|c|}
\hline $\begin{array}{c}\text { Course Unit } \\
\text { (Discipline area) }\end{array}$ & Embedding activity & Main data sources \\
\hline \multicolumn{3}{|l|}{ Year $1(2012 / 13)$} \\
\hline $\begin{array}{r}\text { Power and Protest } \\
\text { (Sociology) }\end{array}$ & $\begin{array}{l}\text { 'Are the young politically disengaged?' } \\
\text { Debating the evidence from survey } \\
\text { data with added data sourcing activity. }\end{array}$ & $\begin{array}{l}\text { British Social Attitudes } \\
\text { Survey (BSA); Audit of } \\
\text { Political Engagement }\end{array}$ \\
\hline $\begin{array}{r}\text { Sociology of } \\
\text { Personal Life } \\
\text { (Sociology) }\end{array}$ & $\begin{array}{l}\text { Tutorial on living alone using survey } \\
\text { data on solo living and the } \\
\text { characteristics of those living alone. }\end{array}$ & Understanding Society \\
\hline $\begin{array}{r}\text { Introduction to } \\
\text { Comparative } \\
\text { Politics (Politics) } \\
\end{array}$ & $\begin{array}{l}\text { Lecture and tutorial examining } \\
\text { attitudes towards immigration in the } \\
\text { class and for the population }\end{array}$ & $\begin{array}{l}\text { Student generated data; } \\
\text { British Social Attitudes } \\
\text { (BSA) }\end{array}$ \\
\hline $\begin{array}{l}\text { Politics of Policy } \\
\text { Making (Politics) }\end{array}$ & $\begin{array}{l}\text { Tutorial on 'Agenda setting' relating } \\
\text { public opinion to data from the Speech } \\
\text { from the Throne. }\end{array}$ & UK Policy Agendas Project \\
\hline $\begin{array}{r}\text { Sociology } \\
\text { Dissertation } \\
\text { (Sociology) }\end{array}$ & $\begin{array}{l}\text { Lecture, guidebook and drop-in } \\
\text { sessions to Support students to use } \\
\text { quantitative data in their dissertations. }\end{array}$ & $\begin{array}{l}\text { UK Data Service, Census; } \\
\text { British Social Attitudes } \\
\text { Information System }\end{array}$ \\
\hline \multicolumn{3}{|l|}{ Year $2(2013 / 2014)$} \\
\hline $\begin{array}{r}\text { British Society and } \\
\text { Culture } \\
(\text { Sociology })\end{array}$ & $\begin{array}{l}\text { Embedding data on ethnicity and class } \\
\text { inequalities into lecture and tutorial } \\
\text { materials. }\end{array}$ & $\begin{array}{l}2011 \text { Census; } \\
\text { Neighbourhood Statistics; } \\
\text { Gapminder; OECD }\end{array}$ \\
\hline $\begin{array}{r}\text { Urban Sociology } \\
\text { (Sociology) }\end{array}$ & $\begin{array}{l}\text { Embedding in lectures and tutorial and } \\
\text { identifying sources of data for students } \\
\text { to use in coursework. }\end{array}$ & Neighbourhood statistics; \\
\hline $\begin{array}{r}\text { Research and study } \\
\text { skills } \\
\text { (Politics) }\end{array}$ & $\begin{array}{l}\text { Workshops on inequality and civic } \\
\text { participation examining attitudinal and } \\
\text { behaviour differences. }\end{array}$ & $\begin{array}{l}\text { Student data; British Social } \\
\text { Attitudes (BSA); British } \\
\text { Election Studies (BES) }\end{array}$ \\
\hline $\begin{array}{r}\text { Politics Project } \\
\text { (Politics) }\end{array}$ & $\begin{array}{l}\text { Student led survey on attitudes towards } \\
\text { immigration, including experiments in } \\
\text { question wording. }\end{array}$ & Student generated data \\
\hline $\begin{array}{r}\text { Racism\& Ethnicity } \\
\text { in the UK } \\
\text { (Sociology) }\end{array}$ & $\begin{array}{l}\text { Identified relevant data to embed in } \\
\text { lectures or tutorials. }\end{array}$ & $\begin{array}{l}2011 \text { Census; Dynamics of } \\
\text { diversity: Evidence from the } \\
2011 \text { census ESRC Centre } \\
\text { on Dynamics of Ethnicity }\end{array}$ \\
\hline $\begin{array}{r}\text { The Sociology of } \\
\text { Spirituality } \\
\text { (Sociology) }\end{array}$ & $\begin{array}{l}\text { Identified relevant data to embed in } \\
\text { lectures or tutorials. }\end{array}$ & $\begin{array}{l}\text { World Values Survey } \\
\text { (WVS); Office for National } \\
\text { Statistics (ONS); Pew } \\
\text { Research Center }\end{array}$ \\
\hline $\begin{array}{r}\text { Gender Sexuality } \\
\text { and Cultures } \\
(\text { Sociology) }\end{array}$ & $\begin{array}{l}\text { Identified relevant data to embed in } \\
\text { lectures or tutorials. }\end{array}$ & $\begin{array}{l}\text { The National Survey of } \\
\text { Sexual Attitudes and } \\
\text { Lifestyles; British Social } \\
\text { Attitudes; OECD }\end{array}$ \\
\hline $\begin{array}{r}\text { Work, Economy \& } \\
\text { Society (Sociology) }\end{array}$ & $\begin{array}{l}\text { Identified areas for embedding } \\
\text { quantitative data. }\end{array}$ & - \\
\hline
\end{tabular}


Table 2: Student attitudes towards quantitative data and methods in their degree

\begin{tabular}{|c|c|c|c|c|c|c|c|}
\hline & 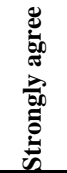 & 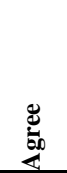 & 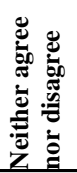 & 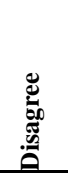 & 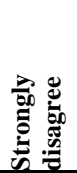 & 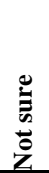 & हี \\
\hline $\begin{array}{l}\text { Quantitative data } \\
\text { helped me make sense } \\
\text { of the theory }\end{array}$ & 8.2 & 60.3 & 24.7 & 5.5 & 0 & 1.4 & 100 \\
\hline $\begin{array}{l}\text { It was difficult to } \\
\text { understand the } \\
\text { quantitative data }\end{array}$ & 2.7 & 16.4 & 21.9 & 47.9 & 11 & 0 & 100 \\
\hline $\begin{array}{l}\text { I enjoyed looking at } \\
\text { the numbers }\end{array}$ & 5.5 & 21.9 & 46.6 & 20.5 & 5.5 & 0 & 100 \\
\hline $\begin{array}{l}\text { The quantitative data } \\
\text { distracted from the } \\
\text { main topic }\end{array}$ & 2.8 & 11.1 & 30.6 & 47.2 & 8.3 & 0 & 100 \\
\hline $\begin{array}{l}\text { The quantitative data } \\
\text { related to the main } \\
\text { topics well }\end{array}$ & 7 & 62 & 28.2 & 2.8 & 0 & 0 & 100 \\
\hline $\begin{array}{l}\text { Seeing tables and } \\
\text { graphs has helped me } \\
\text { to feel more confident } \\
\text { looking at numbers }\end{array}$ & 2.8 & 5.6 & 38.9 & 45.8 & 6.9 & 0 & 100 \\
\hline $\begin{array}{l}\text { More quantitative } \\
\text { data should be used in } \\
\text { teaching }\end{array}$ & 8.2 & 38.4 & 30.1 & 20.5 & 1.4 & 1.4 & 100 \\
\hline $\begin{array}{l}\text { I don't think social } \\
\text { science students } \\
\text { should have to study } \\
\text { statistics }\end{array}$ & 4.1 & 15.1 & 17.8 & 45.2 & 16.4 & 1.4 & 100 \\
\hline $\begin{array}{l}\text { Learning to interpret } \\
\text { and analyse numerical } \\
\text { data is a useful part of } \\
\text { a degree }\end{array}$ & 21.9 & 56.2 & 15.1 & 4.1 & 1.4 & 1.4 & 100 \\
\hline $\begin{array}{l}\text { I am interested in } \\
\text { learning how to } \\
\text { interpret and use } \\
\text { quantitative data }\end{array}$ & 13.7 & 42.5 & 17.8 & 20.5 & 2.7 & 2.7 & 100 \\
\hline
\end{tabular}

$N=73$, The data derived from a survey of students from 3 course units within Sociology and Politics at the University of Manchester. The survey took place in either a lecture or tutorial at the end of the semester, following all embedding activities. For 1 unit large unit, data comes from 3 tutorial groups with the following response rates Group $A=60 \%$, Group B $=80 \%$ and Group $C=67 \%$. For other two course units, data comes from the whole class with response rates of $69 \%$ and $53 \%$. The response rates primarily reflect non-attendance by students.

Note: Darker cells indicate more common responses 
Figure 1: Student views of the benefits of learning quantitative skills

Percentage of students indicating that 'Learning to interpret and analyse quantitative data can help with...'

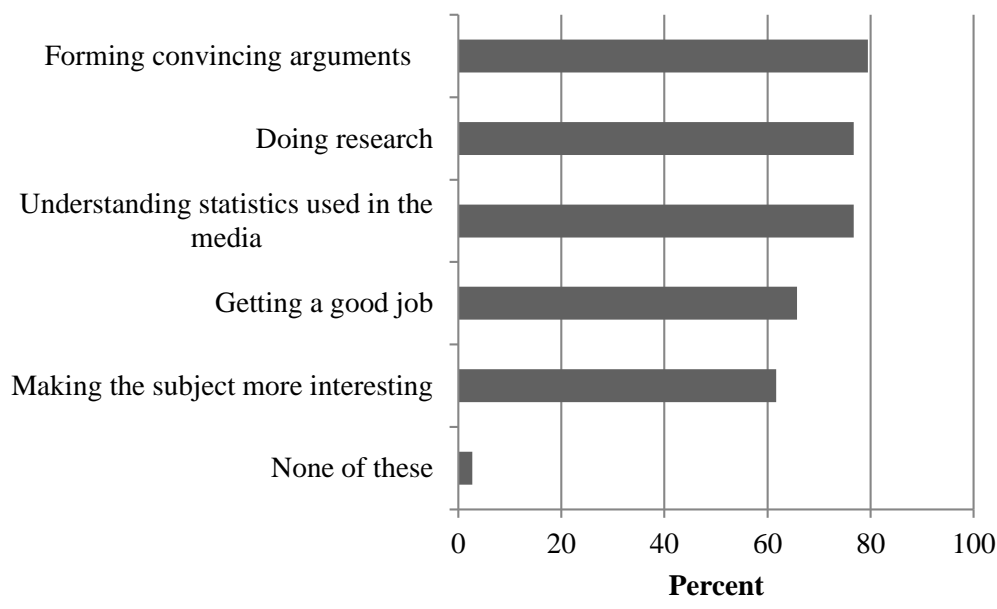

$N=73$, Students from 3 course units within Sociology and Politics at the University of Manchester, see table 2 for details of the sample. 